\title{
Are children and adolescents with type 1 diabetes in Saudi Arabia safe at school?
}

Aqeel A. Alaqeel, MD.

\begin{abstract}

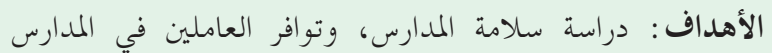

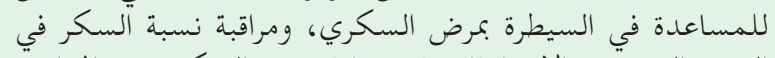

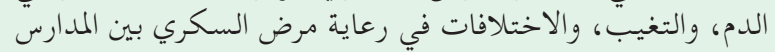

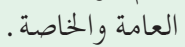

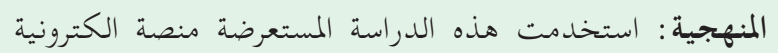

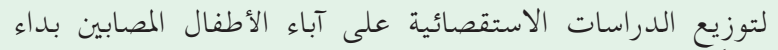

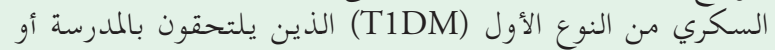

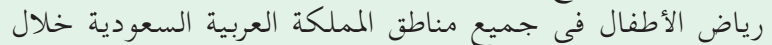

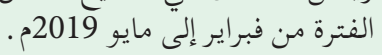

النتائج: تم الانتهاء من الاستبيانات الواردة 411 معظمهم من

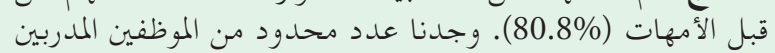

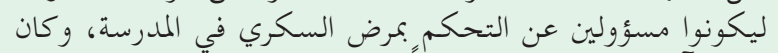

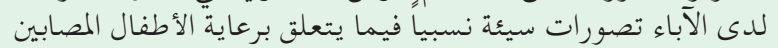

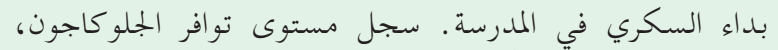

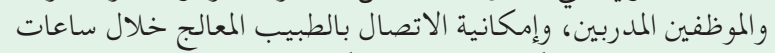

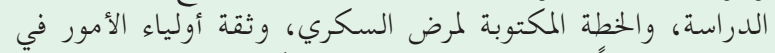

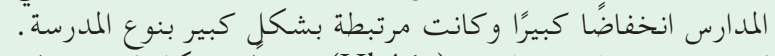

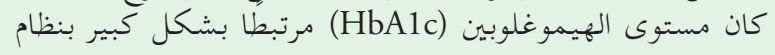

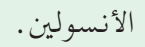

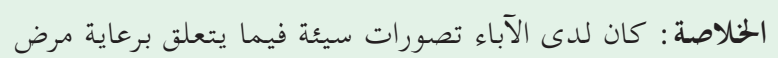

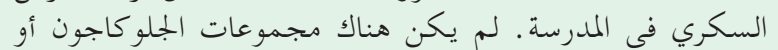

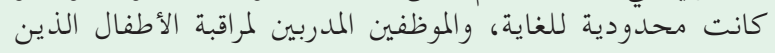

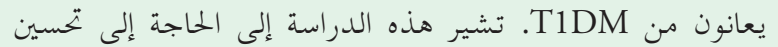
التحكم بمرض السكري في المدارس تشن
\end{abstract}

Objectives: To examined the safety of schools, availability of school personnel to help in diabetes management, glycemic control, absenteeism, and differences in diabetes care between public and private schools.

Methods: This cross-sectional study used an online platform to circulate surveys to parents of children with type 1 diabetes mellitus (T1DM) attending school or kindergarten in all regions of Saudi Arabia from February to May 2019.
Results: The 411 questionnaires received were completed mostly by mothers $(80.8 \%)$. Limited trained staff were found to be responsible for management of diabetes at school, and parents had relatively poor perceptions regarding the care of children with diabetes at school. Glucagon availability, trained staff, possibility of contacting a treating physician during school hours, a written plan for diabetes, and parents' confidence in schools all scored low and were significantly related to school type. Hemoglobin A1c (HbA1c) level was significantly related to insulin regimen.

Conclusion: Parents had poor perceptions regarding diabetes care at school. There was no or very limited availability of glucagon kits and trained staff for management of children with T1DM. This study suggests a need to improve the management of diabetes at schools.

Saudi Med J 2019; Vol. 40 (10): 1019-1026 doi: $10.15537 /$ smj.2019.10.24582

From the Department of Pediatrics, College of Medicine, Qassim University, Buraidah, Kingdom of Saudi Arabia.

Received 25th June 2019. Accepted 17th September 2019.

Address correspondence and reprint request to: Dr. Aqeel A. Alaqeel, Assistant Professor, Department of Pediatrics, College of Medicine, Qassim University, Buraidah, Kingdom of Saudi Arabia. E-mail:a.alaqeel@qumed.edu.sa ORCID ID: 0000-0003-1681-5338

M anagement of children with type 1 diabetes mellitus (T1DM) is challenging for their families, and it is even more so in the school setting, where such children spend a large part of their day. A school environment that is not equipped for students with diabetes may interfere with glycemic control, putting them at high risk of acute complications. ${ }^{1}$ Little has been published about the safety of schools in Saudi Arabia for children with diabetes mellitus (DM) and whether they meet the standards of care based on guidelines. Since the students spend much of the day at school, a reasonable 
expectation is that school staff are knowledgeable and informed about diabetes management. The guidelines recommend to keep hemoglobin $\mathrm{A} 1 \mathrm{c}$ (HbA1c) $<7.5 \%$ or lower if possible for pediatric age group. ${ }^{2} \mathrm{To}$ achieve the recommended glycemic control, children with T1DM will be on intensive insulin therapy that requires multiple blood glucose checks at school. They will also need at least one insulin injection at school or use of an insulin pump, and possibly continuous glucose monitoring. It will also be necessary to check blood or urine ketone levels if the blood glucose level is high or the child is ill. The school is required to provide appropriate meals and count carbohydrate. Moreover, a designated school staff should be trained in the use of glucagon for severe hypoglycemia. ${ }^{3}$ Alotaibi et al, ${ }^{4}$ reported that most of the schools had staff to help with DM management but 5\% of them were nurses who are considered the appropriate staff for DM care at school. This is unlike the school system in the United States of America (USA), where schools are required to provide a full support to the children with special needs and diabetes. ${ }^{3}$ In this study, we examine the safety of schools in Saudi Arabia for students with diabetes and whether they meet the international guidelines. ${ }^{1-3}$

Methods. This cross-sectional study used a questionnaire survey distributed by an online platform. The surveys were circulated online using Google forms among parents and guardians of T1DM children and adolescents who attend school (private or public) or kindergarten in all regions of Saudi Arabia. The survey was distributed electronically through online media platforms such as Twitter, Instagram, and Facebook groups of T1DM parents during the period from February 2019 to May 2019. The parents were explained about the purpose of the study and confidentiality was assured. The participants were asked to participate in the survey if their child is diagnosed by with T1DM (self-identified).

All Published articles in PubMed on T1DM in Saudi Arabia were reviewed by searching: type 1 diabetes in Saudi Arabia, and adolescents or youth with type 1 diabetes in Saudi Arabia; then all the studies were extensively reviewed by the author if the school subject is included.

Disclosure. Authors have no conflict of interests, and the work was not supported or funded by any drug company.
The questionnaire was adapted from Driscoll et $\mathrm{al}^{5}$ and Amillategui ${ }^{6}$ with modifications then translated to Arabic language by the author. Validation of the questionnaire was performed in 2 steps. First, it was reviewed by 2 pediatric endocrinologist with clinical and research experience then, a pilot study with a sample size of 30 parents of children with T1DM who were not included in this study. The study was conducted in accordance with the principles of the Helsinki Declaration; and the Institutional Review Board of Qassim region approved the study. A sample of online questionnaire is shown in Figure 1.

Demographic information included the child's age, gender, region, grade in school, and whether they attended a private or public school. Also recorded were the duration of diabetes, and insulin regimen. Diabetes control measured by self-reported HbAlc level. Safety of schools for diabetic children was measured by the availability of medical staff or trained personnel to manage diabetes at school, and availability of glucagon injections to treat hypoglycemic coma, as well as access to a contact pediatrician/pediatric endocrinologist to answer school DM related concerns for the patients, or to guide the management. Daily management of diabetes at the school was measured in terms of checking blood glucose, daily of insulin injections, and ability to treat hypoglycemia and/or hyperglycemia.

\section{School Part}

1. Is there glucagon available at school? Mark only one oval.

\section{Yes \\ No \\ I do not know}

2. Is there anybody trained to administer glucagon at school? Mark only one oval.

Yes

No

I do not know

3. Has the child experienced negative comments from peers? Mark only one oval.

Yes

No

I do not know

Figure 1 - Sample of online questionnaire. 
Social problems for diabetic children at school, which is a well-known contributing factor in diabetes management and control, was also addressed. The background of school staff regarding diabetes was also measured by their flexibility in allowing diabetic children to eat during class if necessary, and allowing them access to the bathroom more often than other children. Region and type of school (public versus private) were compared with regard to school safety and glycemic control, based on the American Diabetes Association HbAlc target. ${ }^{2}$ Finally, parents' satisfaction with the school for care of their diabetic children was assessed.

Saudi Arabia consists of 13 regions, and in this study, these were divided into 5 groups, as follows: Eastern, Western, Central, Southern, and Northern region. Exclusion criteria include duration of diabetes of less than 6 months, age younger than 4 years or older than 19 years, and the child is not attending school.

Statistical analysis. As per the Diabetes Atlas (8th edition), 35,000 children and adolescents in Saudi Arabia diagnosed with T1DM. ${ }^{7}$ Thus, the sample size was calculated using Raosoft Sample Size Calculator (Raosoft, Inc; 2004, Seattle, USA,) with a confidence interval of $95 \%$ and desired accuracy at 0.05 level. The calculated sample size was 380 . The sample was increased to a total 430, of these 411 completed the survey $(95 \%)$.

Descriptive statistics had been presented as counts and proportions (\%). The association between dependent variable versus independent variables had been calculated using Chi square test. A p-value cut off point of 0.05 at $95 \%$ CI used to determine statistical significance. All data analyses had been carried out using Statistical Packages for Social Sciences (SPSS) version 21, Armonk, NY: IBM Corp.

Results. There were 411 parents who completed the questionnaire out of 430 (95\% response rate), in most cases this was the mother $(80.8 \%)$, followed by the father $(15.3 \%)$ and a legal guardian $(3.9 \%)$. The age range of the children was from 3 to 19 years, the majority $(43.8 \%)$ being in the $10-14$ years age range. Girls dominated the boys ( $56.7 \%$ vs $43.3 \%)$. Many participants lived in the Central region, followed by the Western, Southern, and Eastern regions, with limited cases from the Northern region. More than $60 \%$ of the children were in the elementary school; the remaining attended intermediate, kindergarten, and secondary school. Of the children, $74.2 \%$ were in public schools and $25.8 \%$ in private schools.
Table 1 summarize the sociodemographic characteristics of the studied population. In more than half of the children it had been more than 2 years since diagnosis of DM, and $17.5 \%$ had a family history of T1DM in a first-degree relative. Nearly all of the children had uncontrolled HbA1c levels (84.9\%), with most $(90.3 \%)$ underwent regular visits to endocrinologists. In the treatment of DM, most used multiple daily injections (MDI) without carbohydrate counting (49.6\%), followed by MDI with carbohydrate

Table 1 - Description of sociodemographic characteristics ( $\mathrm{N}=411)$.

\begin{tabular}{|c|c|}
\hline Study data & n $\quad(\%)$ \\
\hline \multicolumn{2}{|l|}{ Age (years) } \\
\hline 3-9 years & $172(41.8)$ \\
\hline $10-14$ years & $180(43.8)$ \\
\hline$>14$ years & $59(14.4)$ \\
\hline \multicolumn{2}{|l|}{ Gender } \\
\hline Male & $178(43.3)$ \\
\hline Female & $233(56.7)$ \\
\hline \multicolumn{2}{|l|}{ Region } \\
\hline Eastern region & $50(12.2)$ \\
\hline Western region & $132(32.1)$ \\
\hline Central region & $151(36.7)$ \\
\hline Southern region & $60(14.6)$ \\
\hline Northern region & $18(4.4)$ \\
\hline \multicolumn{2}{|l|}{ School level } \\
\hline Kindergarten & $33 \quad(8.0)$ \\
\hline Elementary & $245(59.6)$ \\
\hline Intermediate & $86(20.9)$ \\
\hline Secondary & $47(11.4)$ \\
\hline \multicolumn{2}{|l|}{ School type } \\
\hline Public & $305(74.2)$ \\
\hline Private & $106(25.8)$ \\
\hline \multicolumn{2}{|l|}{ Years since diagnosed with DM } \\
\hline$\leq 2$ years & $180(43.8)$ \\
\hline$>2$ years & $231(56.2)$ \\
\hline \multicolumn{2}{|l|}{ Family history of DM } \\
\hline Yes & $72(17.5)$ \\
\hline No & $339(82.5)$ \\
\hline \multicolumn{2}{|l|}{ HbA1c level } \\
\hline Uncontrolled ( $\geq 7.5 \%)$ & $349(84.9)$ \\
\hline Controlled $(<7.5 \%)$ & $62(15.1)$ \\
\hline \multicolumn{2}{|l|}{ Follow up with endocrine } \\
\hline Yes & $371(90.3)$ \\
\hline No & $40 \quad(9.7)$ \\
\hline \multicolumn{2}{|l|}{ Insulin regimen } \\
\hline Insulin pump & $36(8.8)$ \\
\hline MDI with carbohydrate count & $125(30.4)$ \\
\hline MDI w/o carbohydrate count & $204(49.6)$ \\
\hline Others & $46(11.2)$ \\
\hline \multicolumn{2}{|l|}{ Relation to child } \\
\hline Mother & $332(80.8)$ \\
\hline Father & $63(15.3)$ \\
\hline Legal guardian & $16 \quad(3.9)$ \\
\hline
\end{tabular}


counting (30.4\%); relatively few used an insulin pump $(8.8 \%)$ (Table 1$)$.

Table 2 presents the characteristics of children with T1DM in relation to the type of school (public or private). Statistically significant differences were found in occurrence of hypoglycemic coma $(p=0.035)$, with more cases in public schools. At school, glucagon was significantly more likely to be unavailable $(p=0.001)$, with significantly few staff trained for glucagon injection in both groups $(p=0.002)$. Significantly more children never contacted a treating physician at school $(p \leq 0.001)$. It was found that the children were mostly responsible for their own DM care $(p \leq 0.001)$,

Table 2 - Characteristics of children with type 1 diabetes mellitus (T1DM) according to type of school $(\mathrm{N}=411)$

\begin{tabular}{|c|c|c|c|c|}
\hline Parameters & Overall & Public $(\mathrm{n}=305)$ & $\begin{array}{r}\text { Private } \\
(\mathrm{n}=106)\end{array}$ & P-value \\
\hline Restroom allowance & & & & 0.332 \\
\hline Rarely & $16(3.9)$ & $14(4.6)$ & $2(1.9)$ & \\
\hline Sometimes & $83(20.2)$ & $66(21.6)$ & $17(16.0)$ & \\
\hline Always & $283(68.9)$ & $204(66.9)$ & $79(74.5)$ & \\
\hline I don't know & $29(7.1)$ & $21(6.9)$ & $8(7.5)$ & \\
\hline Snacks during classes allowance & & & & 0.132 \\
\hline Rarely & $56(13.6)$ & $44(14.4)$ & $12(11.3)$ & \\
\hline Sometimes & $100(24.3)$ & 78 (25.6) & $22(20.8)$ & \\
\hline Always & $213(51.8)$ & $148(48.5)$ & $65(61.3)$ & \\
\hline I don't know & $42(10.2)$ & $35(11.5)$ & 7 (6.6) & \\
\hline Negative comments from peers & & & & 0.610 \\
\hline Yes & $120(29.2)$ & $93(30.5)$ & $27(25.5)$ & \\
\hline No & $223(54.3)$ & $163(53.4)$ & $60(56.6)$ & \\
\hline I don't know & $68(16.5)$ & $49(16.1)$ & $19(17.9)$ & \\
\hline Hypoglycemic Coma & & & & $0.035^{\dagger}$ \\
\hline Yes & $52(12.7)$ & $44(14.4)$ & $8(7.5)$ & \\
\hline No & $352(85.6)$ & $258(84.6)$ & $94(88.7)$ & \\
\hline I don't know & $7(1.7)$ & $03(1.0)$ & $4 \quad(3.8)$ & \\
\hline Glucagon availability at school & & & & $0.001^{\dagger}$ \\
\hline Yes & $30(7.3)$ & 14 (4.6) & $16(15.1)$ & \\
\hline No & $323(78.6)$ & $245(80.3)$ & $78(73.6)$ & \\
\hline I don't know & $58(14.1)$ & $46(15.1)$ & $12(11.3)$ & \\
\hline Trained staff for glucagon injection & & & & $0.002^{\dagger}$ \\
\hline Yes & $36(8.8)$ & $18 \quad(5.9)$ & $18(17.0)$ & \\
\hline No & $296(72.0)$ & $229(75.1)$ & $67(63.2)$ & \\
\hline I don't know & $79(19.2)$ & $58(19.0)$ & $21(19.8)$ & \\
\hline School provide proper meals & & & & 0.253 \\
\hline Rarely & $276(67.2)$ & $211(69.2)$ & $65(61.3)$ & \\
\hline Sometimes & $39 \quad(9.5)$ & $28 \quad(9.2)$ & $11(10.4)$ & \\
\hline Always & $13(3.2)$ & $7 \quad(2.3)$ & $6(5.7)$ & \\
\hline I don't know & $83(20.2)$ & $59(19.3)$ & $24(22.6)$ & \\
\hline Child need insulin treatment & & & & 0.469 \\
\hline Yes & $377(91.7)$ & $278(91.1)$ & $99(93.4)$ & \\
\hline No & $34 \quad(8.3)$ & $27 \quad(8.9)$ & 7 (6.6) & \\
\hline Child need Glucagon injection & & & & 0.428 \\
\hline Yes & $314(76.4)$ & $236(77.4)$ & 78 (73.6) & \\
\hline No & 97 (23.6) & $69(22.6)$ & $28(26.4)$ & \\
\hline \multicolumn{2}{|c|}{ Possibility of contacting treating physician during school } & & & $<0.001^{\dagger}$ \\
\hline Never & $254(61.8)$ & $202(66.2)$ & $52(49.1)$ & \\
\hline Rarely & $65(15.8)$ & $52(17.0)$ & $13(12.3)$ & \\
\hline Sometimes & $45(10.9)$ & $28 \quad(9.2)$ & $17(16.0)$ & \\
\hline Always & $47(11.4)$ & $23(7.5)$ & $24(22.6)$ & \\
\hline Person responsible for $D M$ & & & & $<0.001^{\dagger}$ \\
\hline None & $70(17.0)$ & $57(18.7)$ & $13(12.3)$ & \\
\hline Parents or relatives & $55(13.4)$ & $44(14.4)$ & $11(10.4)$ & \\
\hline Teachers or administrators & $77(18.7)$ & $51(16.7)$ & $26(24.5)$ & \\
\hline The child & $200(48.7)$ & $153(50.2)$ & $47(44.3)$ & \\
\hline Healthcare provider & $9(2.2)$ & 0 & $9(8.5)$ & \\
\hline
\end{tabular}


Table 2 - Characteristics of children with type 1 diabetes mellitus (T1DM) according to type of school ( $\mathrm{N}=411)$ (continued).

\begin{tabular}{|c|c|c|c|c|}
\hline Responsible for glucose checking & & & & $<0.001^{\dagger}$ \\
\hline None & $75(17.0)$ & $60(19.7)$ & $15(14.2)$ & \\
\hline Parents or relatives & $46(11.2)$ & $35(11.5)$ & $11(10.4)$ & \\
\hline Teachers or administrators & $55(13.4)$ & $34(11.1)$ & $21(19.8)$ & \\
\hline The child & $229(55.7)$ & $176(57.7)$ & $53(50.0)$ & \\
\hline Healthcare provider & $6(1.5)$ & 0 & $6(5.7)$ & \\
\hline Responsible for insulin administration & & & & $<0.001^{\dagger}$ \\
\hline None & $133(32.4)$ & $103(33.8)$ & $30(28.3)$ & \\
\hline Parents or relatives & $77(18.7)$ & $51(16.7)$ & $26(24.5)$ & \\
\hline Teachers or administrators & 20 & $16(5.2)$ & $4 \quad(3.8)$ & \\
\hline The child & $171(41.6)$ & $135(44.3)$ & $36(34.0)$ & \\
\hline Healthcare provider & $10 \quad(2.4)$ & 0 & $10 \quad(9.4)$ & \\
\hline Written plan of DM from physician & & & & $0.002^{\dagger}$ \\
\hline Yes & $45(10.9)$ & $24 \quad(7.9)$ & $21(19.8)$ & \\
\hline No & $321(78.1)$ & $249(81.6)$ & $72(67.9)$ & \\
\hline I don’t know & $45(10.9)$ & $32(10.5)$ & $13(12.3)$ & \\
\hline Embarrassed at school & & & & 0.230 \\
\hline Rarely & $145(35.3)$ & $99(32.5)$ & $46(43.4)$ & \\
\hline Sometimes & $143(34.0)$ & $112(36.7)$ & $31(29.2)$ & \\
\hline Always & $83(20.2)$ & $64(21.0)$ & $19(17.9)$ & \\
\hline I don't know & $40 \quad(9.7)$ & $30 \quad(9.8)$ & $10 \quad(9.4)$ & \\
\hline DM Awareness at school & & & & 0.886 \\
\hline Yes & $59(14.4)$ & $43(14.1)$ & $16(15.1)$ & \\
\hline No & $256(62.3)$ & $189(62.0)$ & $67(63.2)$ & \\
\hline I don't know & $96(23.4)$ & $73(23.9)$ & $23(21.7)$ & \\
\hline Child scale of performance at school & & & & 0.271 \\
\hline Satisfactory & $9(2.4)$ & $8 \quad(2.7)$ & $1(1.1)$ & \\
\hline Good & $39(10.2)$ & $30(10.2)$ & $9(10.1)$ & \\
\hline Very good & $89(23.3)$ & $74(25.3)$ & $15(16.9)$ & \\
\hline Excellent & $245(64.1)$ & $181(61.8)$ & $64(71.9)$ & \\
\hline Absence in a school year (days) & & & & 0.761 \\
\hline With absence & $284(69.1)$ & $212(69.5)$ & $72(67.9)$ & \\
\hline No Absence & $127(30.9)$ & $93(30.5)$ & $34(32.1)$ & \\
\hline Confidence in school & & & & $0.010^{\dagger}$ \\
\hline None & $196(47.7)$ & $155(50.8)$ & $41(38.7)$ & \\
\hline Partial & $179(43.6)$ & $130(42.6)$ & $49(46.2)$ & \\
\hline Full & $36 \quad(8.8)$ & $20 \quad(6.6)$ & $16(15.1)$ & \\
\hline DM - diabetes mellitus, Healthca & $\begin{array}{l}\text { ess as number } \\
\text { ider - Physici } \\
\text { test. }{ }^{+} \text {Signific }\end{array}$ & $\begin{array}{l}\text { ercentage }(\%) \\
\text { urse. }{ }^{*} P \text {-value } \\
<0.05 \text { level }\end{array}$ & en calculate & using \\
\hline
\end{tabular}

glucose checking $(p \leq 0.001)$, and insulin administration $(p \leq 0.001)$. It was also found that significantly fewer parents stated that they have received a clear written management plan for DM at school from a treating physician $(p=0.002)$. We further observed a significant association between parents' confidence in the school and school type $(p=0.010)$, with most parents having a poor perception of the school. However, we found statistically insignificant differences between school type regarding the following characteristics: restroom allowance $(p=0.332)$, snacks during classes $(p=0.132)$, negative comments from peers $(p=0.610)$, providing proper meals $(p=0.253)$, insulin treatment $(\mathrm{p}=0.469)$, glucose testing $(p=0.428)$, embarrassment at school $(p=0.230)$, diabetes awareness at school $(p=0.886)$, and absence in a school year $(p=0.761)$.

We further compare glucagon availability at school and selected sociodemographic characteristics of participants in Table 3. Analysis showed a significant difference based on school type $(p=0.001)$, with most children in public school having no glucagon kit available. However, no significant differences were found regarding school level $(p=0.470)$ and region $(p=0.775)$.

We also measured the relationship between HbA1c level and selected characteristics of children with DM at school in Table 4. It was revealed that insulin regimen had a significant relationship with the level of HbA1c $(p \leq 0.001)$; patients with controlled HbA1c levels tended to use an insulin pump or MDI with carbohydrate 
Table 3 - Association between glucagon availability at school and selected sociodemographic characteristics of patients $(\mathrm{N}=411)$.

\begin{tabular}{|c|c|c|c|c|}
\hline \multirow[t]{2}{*}{ Factors } & \multicolumn{3}{|c|}{ Glucagon availability } & \multirow[t]{2}{*}{$P$-value* } \\
\hline & $\begin{array}{c}\text { Yes } \\
(\mathbf{n}=30)\end{array}$ & $\begin{array}{c}\text { No } \\
(\mathrm{n}=323)\end{array}$ & $\begin{array}{l}\text { I don't know } \\
\quad(n=58)\end{array}$ & \\
\hline School type & & & & $0.001^{\dagger}$ \\
\hline Public & $14(46.7)$ & 245 (75.9) & $46(79.3)$ & \\
\hline Private & $16(53.3)$ & $78(24.1)$ & $12(20.7)$ & \\
\hline School level & & & & 0.470 \\
\hline Elementary or kindergarten & $23(76.7)$ & $218(67.5)$ & $37(63.8)$ & \\
\hline Intermediate or secondary & $7(23.3)$ & $105(32.5)$ & $21(36.2)$ & \\
\hline Region & & & & 0.775 \\
\hline Eastern region & $5(16.7)$ & 38 (11.8) & 07 (12.1) & \\
\hline Western region & $10(33.3)$ & $101(31.3)$ & $21(36.2)$ & \\
\hline Central region & $11(36.7)$ & $117(36.2)$ & $23(39.7)$ & \\
\hline Southern region & $4(13.3)$ & $50(15.5)$ & $6(10.3)$ & \\
\hline Northern region & 0 & $17(05.3)$ & $1(01.7)$ & \\
\hline Values are express as number & $\begin{array}{l}\text { ercentage } \\
{ }^{\dagger} \text { Significa }\end{array}$ & $\begin{array}{l}{ }^{*} \mathrm{P} \text {-value has } \\
\mathrm{p}<0.05 \text { leve }\end{array}$ & calculated & chi-square \\
\hline
\end{tabular}

Table 4 - Relationship between Hemoglobin A1c (HbA1c) level and selected characteristics of patients with type 1 diabetes mellitus (T1DM) at school $(\mathrm{N}=411)$.

\begin{tabular}{|c|c|c|c|}
\hline Factors & $\begin{array}{c}\text { Uncontrolled } \\
(\mathrm{n}=349)\end{array}$ & $\begin{array}{c}\text { Controlled } \\
(n=62)\end{array}$ & $P$-value* \\
\hline \multicolumn{4}{|l|}{ School type } \\
\hline Public & $263(75.4)$ & $42(67.7)$ & 0.207 \\
\hline Private & $86(24.6)$ & $20(32.3)$ & \\
\hline \multicolumn{4}{|l|}{ School level } \\
\hline Elementary or kindergarten & $242(69.3)$ & $36(58.1)$ & 0.080 \\
\hline Intermediate or secondary & $107(30.7)$ & $26(41.9)$ & \\
\hline \multicolumn{4}{|l|}{ Insulin regimen } \\
\hline MDI with carbohydrate count/pump & $119(34.1)$ & $42(67.7)$ & $<0.001^{\dagger}$ \\
\hline MDI w/o carbohydrate count/others & $230(65.9)$ & $20(32.3)$ & \\
\hline \multicolumn{4}{|l|}{ School performance rating scale } \\
\hline Very good and below & $125(38.5)$ & $12(21.1)$ & $0.011^{\dagger}$ \\
\hline Excellent & $200(61.5)$ & $45(78.9)$ & \\
\hline \multicolumn{4}{|l|}{ Absence in a school year (days) } \\
\hline With absence & $243(69.6)$ & $41(66.1)$ & 0.583 \\
\hline No absence & $106(30.4)$ & $21(33.9)$ & \\
\hline
\end{tabular}

counting. We also detected that increasing child performance at school was associated with controlled HbA1c levels $(p=0.011)$, whereas school type, school level, and absence in a school year had no significant relationship with level of $\mathrm{HbA1c}$.

Discussion. The present study aimed to examine safety of schools and availability of trained staff who may assist in the management of children with T1DM and glycemic control, taking into consideration parents perceptions of the 2 types of school (public versus private) and how they care about children with this disease. We view this as the first survey in Saudi Arabia to tackle this subject, which is important since T1DM is widely regarded as one of the most common chronic diseases moreover, Saudi Arabia has been ranked seventh in prevalence worldwide., ${ }^{7,8}$ In order to achieve a safe school for students with T1DM, glucagon injections should always be available, since this is the only approved first-line therapy for severe hypoglycemia (loss of consciousness and/or seizures). ${ }^{3}$ However, in this study most parents indicated that there was limited availability of glucagon injections at school 
(7\%), and trained staff for administration of glucagon was also deemed insufficient $(8.6 \%)$. These percentages should be close to $100 \%{ }^{2,3}$ Unavailability of glucagon or lack of trained staff at school is considered unsafe, as severe hypoglycemia in T1DM may lead to seizure, coma, and eventually death. ${ }^{9}$ Unfortunately, $12.7 \%$ of the children in this study had already experienced severe hypoglycemia with coma at school.

With regard to the person responsible for management of DM at school, a high proportion of parents implied that their children were performing the management of DM, glucose checking, and insulin administration. In contrast, in studies in the USA and Spain, the school nurses were responsible of diabetes care. ${ }^{5,6}$ In terms of differences between public and private schools regarding diabetes care, we noticed that public schools had no healthcare provider (namely, nurse or physician) available to assist the children with their diabetes care needs. This is in agreement with the results of a previous study in Saudi Arabia, where a healthcare provider was available in only $5 \%$ of schools. ${ }^{4}$

It is also disappointing to observe that $8 \%$ of children with T1DM are not receiving insulin during school hours; this is likely to have an impact on glycemic control and should be closer to $100 \%$. Insulin therapy should always be available at schools, taking into consideration eating meals and snacks at school and managing sick days. This finding has been corroborated by Amillategui et $\mathrm{al}^{6}{ }^{6}$ who found that most children are checking their glucose level at school but few needed insulin administration. The parents, teachers, and children acknowledged that no glucagon kits were available at school, and surprisingly, teachers were not familiar with glucagon kit indication.

This study also revealed that $29 \%$ of children reported negative comments from peers regarding diabetes, which may also compromise their glycemic control. This may be addressed by establishing a private location at school for glucose testing and insulin administration. ${ }^{10}$ Parents also reported that their children were rarely allowed to eat a snack in the classroom (13\%), to use the restroom if necessary $(4 \%)$, or provided with a proper meal for the diabetes setting (67\%). In addition, $79 \%$ of children child had no written care plan at their school. Such a plan is recommended for daily DM management at school in order to maintain glycemic control and prevent DM acute complications. ${ }^{3}$ In this study, the parents had a poor perception of diabetes care at schools. This result is in agreement with the findings of Jacquez et $\mathrm{al}^{11}$ in their assessment of parents' perspectives of diabetes management in schools. Another notable finding in this study was the high prevalence of uncontrolled HbA1c levels (85\%); the inadequate DM management at school can be a potential factor.

Furthermore, we assessed differences between school types regarding characteristics of children with T1DM at school. We determined that private schools had more glucagon availability, trained staff for glucagon injection, a written plan for DM from treating physician, easy access to the treating physician during school hours, a person responsible for DM care at school, child performance scale, and parents' confidence in the school. These findings confirmed better DM care at private schools. When measuring the association between $\mathrm{HbA1c}$ level and selected characteristics of patients with T1DM, we detected that insulin regimen and child performance scale at school are significantly associated with $\mathrm{HbA1c}$ level.

With regard to the insulin regimen for treatment of DM, only $39 \%$ of the children were using MDI with carbohydrate counting or an insulin pump, the standard for care in T1DM. ${ }^{2}$ Furthermore, it is notable that $17.8 \%$ of subjects had a first-degree relative with T1DM (father 5.3\%, mother 4.3\%, sibling 8.2\%); a study in Finland revealed $12.2 \%$ to have a first-degree relative with T1DM. ${ }^{12}$

We trust that this is the first paper to elaborate on these types of criteria. Although some previously published papers determined the relationship between characteristics of DM at school against certain groups, none presented the association between $\mathrm{HbAlc}$ level against sociodemographic characteristics. Thus, we hope that the findings of this study can be used for reference for future research.

Taken together, the results of this study reveal that schools in Saudi Arabia have not met the standard level of care for safety for children with diabetes., ${ }^{2,3}$ These results also highlight the need to improve schools DM care.

There are several limitations of this study, including that it relied on parents' reports about diabetes care in the school rather than observational measures. Also, $\mathrm{HbA1c}$ levels were self-reported and the technique may vary between regions and hospitals. School staff who help in DM care may be included in future research.

Finally, there is a need for ministries of education and health to take initiatives developing a safe school environment for the T1DM students. The plan may include (i) a trained nurse or healthcare provider should be always available at school or instead implementing a strategies for training school personnel, (ii) provide a written diabetes medical management including medication direction, timing and emergency plan 
including sick-day management. Additionally, (iii) create a school policy that every child with DM is required to have glucagon kit, (iv) ask diabetes educator or endocrinologist to educate school nurses and the staff, parents also are encouraged for educating the staff, (v) provides material and links for school staff education. Resources are ADA guidelines, ${ }^{10}$ Colorado kids with diabetes websites, ${ }^{13}$ American Association of Diabetes Educators. ${ }^{14}$

In conclusion, the parents of children and adolescents with T1DM in this study had a very low perception of diabetes care at their schools. Availability of glucagon kits and trained staff at school for management of children with T1DM were either non-existent or very limited. This study suggests the need to improve the management of diabetes at school. Cultivation of a diabetes care plan is necessary; this includes interventions involving healthcare providers, parents, teachers, and the school administration to enable complete assimilation of these groups of children at school.

We further discovered that private schools had better DM care compared to public schools with regard to glucagon availability, trained staff for glucagon injection, possibility of contacting a treating physician during school, nurses responsible for DM care, a written plan for DM from the treating physician, and parents' confidence in the school. Moreover, students who tend to have a controlled HbA1c level are likely to have glucagon kits available at their school. In addition, the insulin regimen and child's performance at school are statistically related to their HbA1c level.

Acknowledgment. The author gratefully acknowledge Dr. Bassam Bin-Abba (Professor of Pediatrics and Endocrinology, King Faisal Specialist Hospital and Research Center, Saudi Arabia) and Dr.Ahmed Nahari (Pediatric Endocrinologist, King Fahad Central Hospital, Jazan, Saudi Arabia) for reviewing the questionnaire and to Dr.Ricardo Gomez (Associate Professor of Clinical Pediatrics, Louisiana State University Health Sciences Center and Children's Hospital, USA) for valuable comments on the manuscript. The author would also like to thank Editage (http://www.editage.com) for editing and reviewing this manuscript for English language”

\section{References}

1. Chiang JL, Maahs DM, Garvey KC, Hood KK, Laffel LM, Weinzimer SA, et al. Type 1 diabetes in children and adolescents: A position statement by the American Diabetes Association. Diabetes Care 2018; 41: 2026-244.

2. Children and Adolescents: Standards of Medical Care in Diabetes-2019. Diabetes Care 2019; 42 (Suppl 1): S148-S164.

3. Bratina N, Forsander G, Annan F, Wysocki T, Pierce J, Calliari LE, et al. ISPAD Clinical Practice Consensus Guidelines 2018: Management and support of children and adolescents with type 1 diabetes in school. Pediatr Diabetes 2018; 19: 287-301.

4. Alotaibi M, Alibrahim L, Alharbi N. Challenges associated with treating children with diabetes in Saudi Arabia. Diabetes Res Clin Pract 2016; 120: 235-2340.

5. Driscoll KA, Volkening LK, Haro H, Ocean G, Wang Y, Jackson CC, et al. Are children with type 1 diabetes safe at school? Examining parent perceptions. Pediatr Diabetes 2015; 16: 613-620.

6. Amillategui B, Mora E, Jr C, Special GP. Special needs of children with type 1 diabetes at primary school: perceptions from parents, children, and teachers. Pediatr Diabetes 2009; 10: 67-73.

7. International Diabetes Federation. IDF diabetes atlas. 8th ed. [cited 2017]. Available from: http://diabetesatlas.org/ resources/2017-atlas.html

8. Centers for Disease Control and Prevention. National Diabetes Statistics Report [2018 February 14]. Available from: https:// www.cdc.gov/diabetes/data/statistics/statistics-report.html

9. Lehecka KE, Renukuntla VS, Heptulla RA. Insight into hypoglycemia in pediatric type 1 diabetes mellitus. Int J Pediatr Endocrinol 2012; 2012: 19.

10. Association AD. Diabetes care in the school and day care setting. Diabetes Care 2010; 33 Suppl 1: S70-S74.

11. Jacquez F, Stout S, Alvarez-Salvat R, Fernandez M, Villa M, Sanchez J, et al. Parent perspectives of diabetes management in schools. Diabetes Educ 2008; 34: 996-1003.

12. Parkkola A, Harkonen T, Ryhanen SJ, Ilonen J, Knip M. Extended family history of type 1 diabetes and phenotype and genotype of newly diagnosed children. Diabetes Care 2013; 36 : 348-354.

13. Colorado Kids With Diabetes. School Handouts. Kids with diabetes [cited 2019 September 12]. Available from: https:// www.coloradokidswithdiabetes.org/

14. American Association of Diabetes Educators. Management of children with diabetes in the school setting AADE position statement. [Updated 2019; Accessed 2019 Sep 12]. Available from: https:/www.diabeteseducator.org/ 